\title{
Histogram Profil Proyeksi sebagai Metode Ekstraksi Fitur pada Pengenalan Karakter Tulisan Tangan
}

\author{
Fetty Tri Anggraeny ${ }^{1}$, M. Syahrul Munir ${ }^{2 *}$, Intan Yuniar Purbasari ${ }^{3}$ \\ ${ }^{1,2,3}$ Informatika, Universitas Pembangunan Nasional "Veteran” Jawa Timur \\ ${ }^{2}$ syahrul.attraktiv@gmail.com \\ *Corresponding author email: ${ }^{1}$ fettyanggraeny.if@upnjatim.ac.id
}

\begin{abstract}
Abstrak- Penelitian tentang pengenalan karakter masih sangat diminati sampai saat ini karena area aplikasinya yang luas. Topik penelitiannya dapat terkait dengan preprocessing, ekstraksi fitur dan metode pengenalan karakter. Dalam bidang pengenalan karakter ada beberapa metode ekstraksi fitur yang dapat digunakan, salah satunya profil proyeksi. Profil proyeksi adalah suatu histogram yang memproyeksikan piksel citra kearah horisontal maupun vertikal. Histogram proyeksi menghitung jumlah piksel non-background pada arah spesifik tertentu, horisontal dan vertikal. Dalam penelitian ini dilakukan analisa terhadap penggunakan proyeksi vertikal, horisontal, dan gabungan terhadap karakter huruf Roman yang diklasifikasi menggunakan k-NN. Hasil dari penelitian ini memberikan performa akurasi terbaik $\mathbf{8 0 , 9 5 \%}$ dengan waktu yang dibutuhkan 0,66 detik.
\end{abstract}

Kata Kunci- profil proyeksi, karakter roman, tulisan tangan, knearest neighbor

\section{Pendahuluan}

Optical Character Recognition (OCR) merupakan suatu proses mengenali karakter tersegmentasi dari dokumen yang dipindai menjadi citra berdasarkan fitur yang diekstrak dari gambar karakter tersebut [1]. Penelitian tentang pengenalan karakter masih sangat diminati sampai saat ini karena area aplikasinya yang luas. Topik penelitiannya dapat terkait dengan preprocessing, ekstraksi fitur dan metode pengenalan karakter.

Dalam bidang pengenalan karakter ada beberapa metode ekstraksi fitur yang dapat dilakukan. Soora membahas dalam penelitiannya membagi fitur menjadi 2 kelompok, yaitu fitur berbasis bentuk dan fitur tidak berbasis bentuk [2]. Salah satu fitur tidak berbasis bentuk adalah profil proyeksi yang merupakan fitur statistic. Dari beberapa paper yang di review, pemakaian variasi profil proyeksi sebagai fitur memberikan performa yang cukup bagus.

Jika umumnya OCR memproses gambar dokumen yang terdiri dari objek karakter ketikan. Ada bidang pengenalan karakter yang tidak kalah menarik, yaitu pengenalan karakter tulisan tangan. Selain tulisan tangan berbentuk alphabet baku, di beberapa wilayah dunia memiliki huruf daerah yang unik. Misalnya di pulau Jawa Indonesia terdapat aksara jawa yang sering disebut aksara hanacaraka. Dalam jenis karakter yang sama, tulisan tangan sangat beragam tergantung pada si penulis, sehingga hal ini sangat menarik untuk diteliti secara berkelanjutan. Dan salah satu parameter yang menjadi tantangan para peneliti adalah waktu yang dibutuhkan untuk mengenali karakter.

Dalam perkembangannya banyak penelitian yang mengunakan variasi profil proyeksi. Referensi [3] membandingan antara profil proyeksi horisontal, profil proyeksi vertikal dan run histogram pada dokumen. Uicoba menunjukkan bahwa profil proyeksi vertikal membutuhkan waktu lebih lama daripada 2 proyeksi yang lain. Non-linear multi-projection menggunakan radon transform menggunakan karakter Romawi (aksara yang biasa kita gunakan A-Z, 0-9). Ujicoba menunjukkan pada karakter Roman baik berupa angka, huruf, dan symbol memberikan performa yang sangat bagus $100 \%$ akurasi pada parameter transformasi radon $180^{\circ}$ [4]. Penelitian lain menggunakan zona proyeksi, antara lain proyeksi vertikal zona atas, proyeksi vertikan zona bawah, proyeksi horisontal zona kiri, dan proyeksi horisontal zona kanan. Dengan menggunakan mesin klasifikasi EMDC dan SVM memberikan akurasi $83 \%$ dan $90 \%$ [5]. Pengenalan huruf Bangla yang menggunakan proyeksi vertikal dan horisontal menunjukkan performa yang sangat tinggi. Dalam penelitian ini juga menunjukkan bahwa dengan penambahan proses skeletoning, performa yang dihasilkan menjadi maksimal [6]. Penelitian yang juga menggunakan proyeksi vertikal, horisontal dan gabungan pada dataset karakter Gurmukhi memberikan hasil bahwa penggabungan proyeksi vertikal dan horisontal memberikan peningkatan performa yang cukup pada keseluruhan sistem [7].

Penelitian sebelumnya [8], [9] memiliki kelemahan terutama pada waktu proses, selain itu beberapa metode klasifikasi juga menunjukkan performa yang tidak terlalu baik jika dibandingkan dengan waktu yang dibutuhkan. Oleh karena itu, dalam penelitian ini digunakan metode ekstraksi fitur yang lebih cepat untuk memangkas proses pengenalan karakter.

\section{METODOLOGI}

Dalam penelitian ini, digunakan profil proyeksi citra untuk mengekstraksi fitur citra karakter tulisan tangan yang umumnya digunakan sebagai metode segmentasi. Metodologi dalam penelitian ini disajikan pada Gbr. 1 .

Pertama, citra input dilakukan ekstraksi bounding box untuk mendapatkan ROI. Kedua, citra ROI yang ukurannya beragam, disamakan menjadi ukuran 32×32 piksel. Ketiga, dilakukan ekstraksi skeleton untuk mendapatkan tulang dari 
karakter. Keempat, ekstraksi fitur menggunakan profil proyeksi citra menggunakan arah vertikal, horisontal dan kombinasinya. Kelima, proses klasifikasi menggunakan k-NN yang akan diuji coba dengan beberapa varian nilai parameter $\mathrm{k}$. Keenam, output label dari k-NN adalah angka kelas.

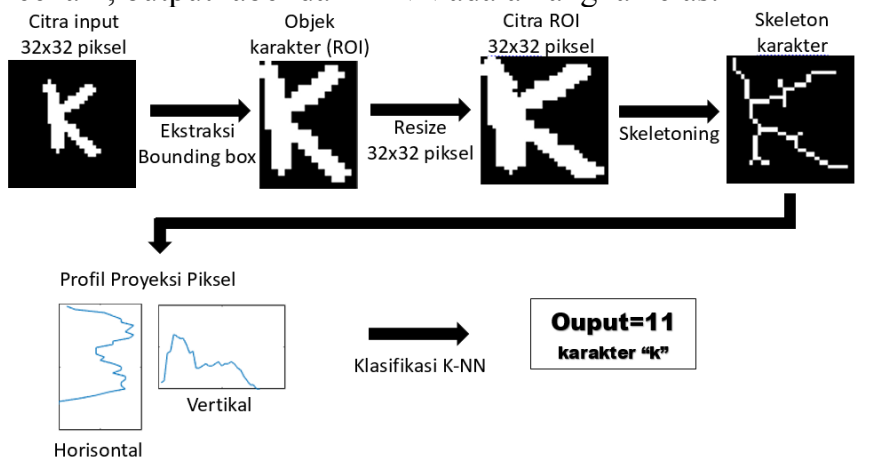

Gbr. 1 Metodologi.

\section{A. Ekstraksi Bounding Box}

Tahapan ekstraksi bounding box sangat penting dalam aplikasi yang menggunakan citra. Dengan mengekstraksi bounding box, data penelitian focus pada Region of Interest (ROI) citra, dengan cara mengeliminasi bagian citra yang tidak sesuai dengan fokus penelitian. Perintah Pemrograman MATLAB yang digunakan untuk mendapatkan bounding box adalah

pic3=regionprops (pic2, 'BoundingBox') ;

kemudian untuk mendapatkan citra ROI dilakukan proses crop dengan perintah:

imcrop (pic, rec.BoundingBox);

Ilustrasi proses mendapatkan citra ROI, dapat dilihat pada Gbr. 2.

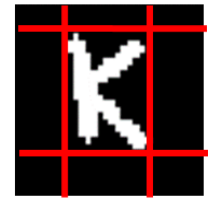

(a)

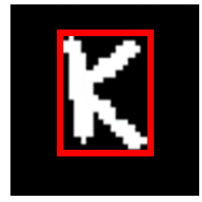

(b)

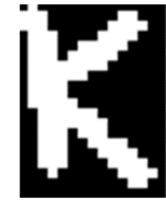

(c)
Gbr. 2 Proses ekstraksi bounding box (a) batas piksel terluar, (b) hasil bounding box, and (c) citra ROI

\section{B. Penyeragaman ukuran citra ROI}

Citra ROI hasil bounding box ukurannya sangat beragam, sehingga diperlukan penyeragaman ukuran piksel untuk proses berikutnya. Ukuran yang digunakan adalah $32 \times 32$ piksel sesuai dengan ukuran data semula. Perintah MATLAB yang digunakan:

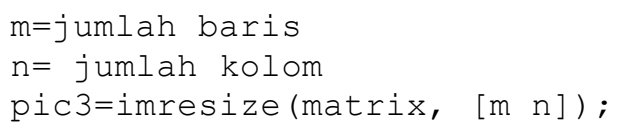

Dengan menggunakan perintah imresize(), citra ROI yang ukurannya bervariasi dapat diseragamkan, lihat Gbr. 1.

\section{Ekstraksi skeleton}

Skeleton adalah bentuk objek dengan ketebalan 1 piksel yang merepresentasikan tulang objek. Proses mendapatkan skeleton mengunakan metode morfologi erosi dan open secara berulang sampai mendapat garis dengan ketebalan 1 piksel. $A$ adalah citra awal, $B$ struktur elemen dan $S(A)$ citra skeleton. $B$ dioperasikan ke seluruh bagian citra secara iteratif $(k)$ sampai mendapatkan garis ketebalan 1 piksel yang disebut sebagai tulang (skeleton).

$$
\begin{aligned}
& S(A)=\bigcup_{k=0}^{K} S_{k}(A) \\
& S_{k}(A)=\left(A \ominus^{k B}\right)-\left(A \ominus^{k B}\right) \circ B \\
& (A \ominus k B)=\left(\left(\ldots\left(A \ominus^{B}\right) \ominus^{B}\right) \ldots\right) \ominus^{B}
\end{aligned}
$$

Perintah MATLAB yang digunakan:

pic4 = bwmorph (pic3,'skel', Inf);

Hasil dari eksekusi code ini dapat dilihat pada Gbr. 1.

\section{Histogram Profil Proyeksi Citra}

Citra skeleton dapat langsung digunakan sebagai data masukan mesin klasifikasi, tetapi akan lebih baik jika dilakukan ekstraksi fitur. Sehingga jumlah masukan mesin klasifikasi lebih sedikit dan lebih memiliki arti terhadap objek yang akan diproses.

Profil proyeksi adalah suatu histogram yang memproyeksikan piksel citra kearah horisontal maupun vertikal. Histogram proyeksi menghitung jumlah piksel nonbackground pada arah spesifik tertentu, horisontal dan vertikal, perhatikan Gbr. 3. Untuk mendapatkan profil proyeksi secara horisontal $(H P P)$ maupun vertikal $(V P P)$ menggunakan rumusan yang sangat sederhana berikut [3]:

$V P P=\sum_{x=1}^{m} f(x, y)$
$H P P=\sum_{y=1}^{n} f(x, y)$

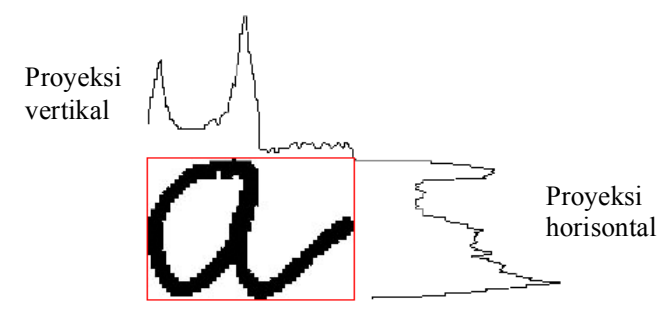

Gbr. 3 Histogram profil proyeksi.

Untuk mendapatkan histogram profil proyeksi karakter tulisan tangan, kode program MATLAB yang digunakan adalah fungsi sum ( ) dengan implementasinya sebagai berikut:

tempV_asli=sum $(\mathrm{pic} 5,1) ;$

Fungsi sum ( ) digunakan karena citra yang diolah adalah citra biner, dimana piksel objek bernilai 1 dan piksel background bernilai 0 .

E. Klasifikasi $k-N N$ 
Klasifikasi k-NN adalah metode klasifikasi sederhana berdasarkan selisih nilai fitur antara data train $(x)$ dengan data uji $(y)$. Metode penghitungan selisih umumnya adalah jarak Euclidean $d(x, y)$ yang ditunjukkan pada rumusan berikut [8]:

$d(x, y)=\sqrt{\sum_{i=1}^{n}\left(x_{i}-y\right)^{2}}$

Setelah menghitung selisih fitur, maka ditentukan nilai parameter $k$-tetangga terdekat. Gbr. 4 mengilustrasikan proses 3-NN, dimana dipilih 3 tetangga terdekat lalu di analisa kelasnya. Data uji akan terklasifikasi menjadi kelas segitiga karena 2 dari 3 tetangga terdekat anggota dari kelas segitiga.

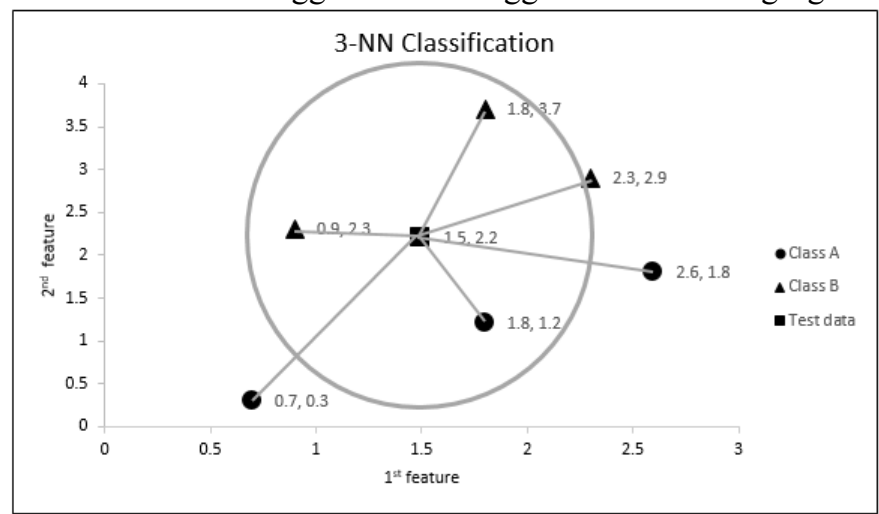

Gbr. 4 Klasifikasi 3-NN.

Klasifikasi k-NN pada MATLAB menggunakan kode program berikut:

$\operatorname{mdl}=$

ClassificationKNN. fit (Xtrain', Ytrain); mdl. NumNeighbors = neigh;

classknn = predict (mdl, Xtest') ' ;

\section{F. Dataset}

Dataset yang digunakan terdiri dari 5588 sample data dengan 26 kelas, huruf kapital atau tidak b di berada di kelas yang sama. Detail distribusi jumlah data setiap kelas ditampilkan pada Tabel I. Setiap data karakter tulisan tangan berukuran $32 \times 32$ piksel yang disimpan dalam bentuk vektor berukuran 1024. Beberapa sampel data dapat dilihat pada Gbr. 5.

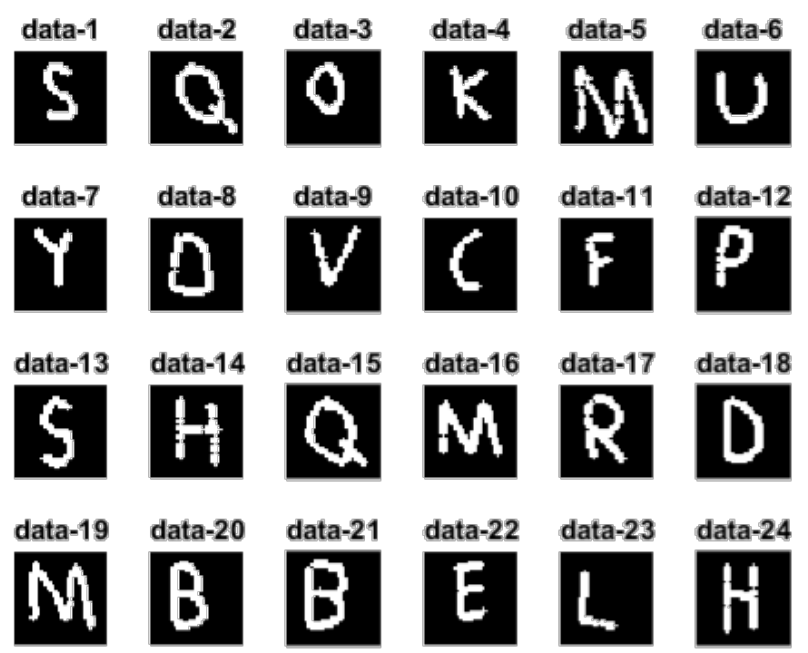

Gbr. 5 Sampel data.

TABEL I

DISTRIBUSI SAMPEL DATA TIAP KELAS

\begin{tabular}{|l|l|l|l|}
\hline Kelas & $\begin{array}{l}\text { Jumlah } \\
\text { sampel }\end{array}$ & Kelas & $\begin{array}{l}\text { Jumlah } \\
\text { sampel }\end{array}$ \\
\hline $0($ karakter a/A) & 210 & $13($ karakter $\mathrm{n} / \mathrm{N})$ & 217 \\
\hline $1($ karakter b/B) & 222 & $14($ karakter o/O) & 209 \\
\hline $2($ karakter $\mathrm{c} / \mathrm{C})$ & 222 & $15($ karakter $\mathrm{p} / \mathrm{P})$ & 220 \\
\hline $3($ karakter d/D) & 208 & $16($ karakter $\mathrm{q} / \mathrm{Q})$ & 210 \\
\hline $4($ karakter e/E) & 198 & $17($ karakter $\mathrm{r} / \mathrm{R})$ & 219 \\
\hline $5($ karakter $\mathrm{f} / \mathrm{F})$ & 242 & $18($ karakter $\mathrm{s} / \mathrm{S})$ & 220 \\
\hline $6($ karakter $\mathrm{g} / \mathrm{G})$ & 222 & $19($ karakter $\mathrm{t} / \mathrm{T})$ & 211 \\
\hline $7($ karakter $\mathrm{h} / \mathrm{H})$ & 196 & $20($ karakter $\mathrm{u} / \mathrm{U})$ & 209 \\
\hline $8($ karakter $\mathrm{i} / \mathrm{I})$ & 208 & $21($ karakter $\mathrm{v} / \mathrm{V})$ & 203 \\
\hline $9($ karakter j/J) & 205 & $22($ karakter $\mathrm{w} / \mathrm{W})$ & 224 \\
\hline $10($ karakter $\mathrm{k} / \mathrm{K})$ & 231 & $23($ karakter $\mathrm{x} / \mathrm{X})$ & 229 \\
\hline $11($ karakter $\mathrm{l} / \mathrm{L})$ & 204 & $24($ karakter $\mathrm{y} / \mathrm{Y})$ & 195 \\
\hline $12($ karakter $\mathrm{m} / \mathrm{M})$ & 211 & $25($ karakter $\mathrm{z} / \mathrm{Z})$ & 243 \\
\hline
\end{tabular}

\section{HASIL DAN PEMBAHASAN}

Beberapa skema ujicoba telah dilakukan, antara lain:

1. Menggunakan variasi nilai jumlah tetangga terdekat k mulai 1 sampai 10.

2. Menggunakan beberapa profil proyeksi, antara lain horisontal, vertikal, dan gabungan.

3. Membandingkan hasil klasifikasi dari citra asli dan citra skeleton untuk setiap jenis profil proyeksi.

4. Perbandingan dengan penelitian sebelumnya.

Gbr. 6-8 menampilkan perbandingan akurasi antara citra asli dan citra skeleton. Tampak pada ketiganya bahwa hasil akurasi pada citra skeleton tidak lebih baik daripada akurasi citra asli. Hal ini dikarenakan dengan mengekstrak skeleton karakter, justru menghilangkan data (piksel objek) yang penting untuk pembentukan informasi profil proyeksi.

Sedangkan Gbr. 9 dan 10 menampilkan perbandingan akurasi penggunaan berbagai jenis profil proyeksi pada jenis citra yang sama (citra asli dan citra skeleton). Kedua grafik ini menunjukkan bahwa penggabungan fitur profil proyeksi horisontal dan vertikal dapat meningkatkan performa sistem dengan sangat baik dibandingkan penggunakan profil proyeksi tunggal (horisontal atau vertikal).

\section{PROFIL PROYEKSI VERTIKAL}

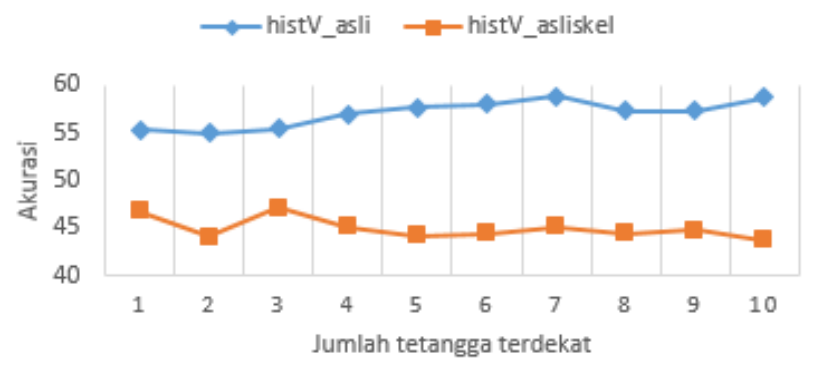

Gbr. 6 Akurasi perbandingan fitur profil proyeksi vertikal pada citra asli dan citra skeleton. 
TABEL II

PERFORMA SISTEM KESELURUHAN UJICOBA

\begin{tabular}{|l|l|l|l|l|l|l|l|l|l|l|l|}
\hline Fitur & $\mathrm{K}=1$ & $\mathrm{~K}=2$ & $\mathrm{~K}=3$ & $\mathrm{~K}=4$ & $\mathrm{~K}=5$ & $\mathrm{~K}=6$ & $\mathrm{~K}=7$ & $\mathrm{~K}=8$ & $\mathrm{~K}=9$ & $\mathrm{~K}=10$ & $\mathrm{R} a t a-$ rata \\
\hline histV_asli & 55.27 & 54.93 & 55.44 & 56.97 & 57.65 & 57.99 & $\mathbf{5 8 . 8 4}$ & 57.31 & 57.31 & 58.67 & 57.038 \\
\hline histH_asli & 63.95 & 59.52 & 63.27 & 63.61 & 65.14 & 64.46 & 64.97 & 65.48 & 65.48 & $\mathbf{6 5 . 9 9}$ & 64.187 \\
\hline histVH_asli & $\mathbf{8 0 . 9 5}$ & 78.57 & 79.42 & 78.91 & 80.10 & 79.25 & 79.25 & 78.74 & 79.93 & 79.59 & $\mathbf{7 9 . 4 7 1}$ \\
\hline histV_asliskel & 46.77 & 44.05 & $\mathbf{4 7 . 1 1}$ & 45.07 & 44.22 & 44.39 & 45.07 & 44.39 & 44.73 & 43.71 & 44.951 \\
\hline histH_asliskel & $\mathbf{5 0}$ & 49.49 & 48.99 & 48.47 & 49.49 & 48.64 & 49.15 & 49.15 & 48.98 & 47.96 & 49.032 \\
\hline histVH_asliskel & 59.01 & 54.76 & $\mathbf{5 9 . 8 6}$ & 59.01 & 58.33 & 56.63 & 57.14 & 57.65 & 55.95 & 56.12 & 57.446 \\
\hline
\end{tabular}

\section{PROFIL PROYEKSI} HORISONTAL

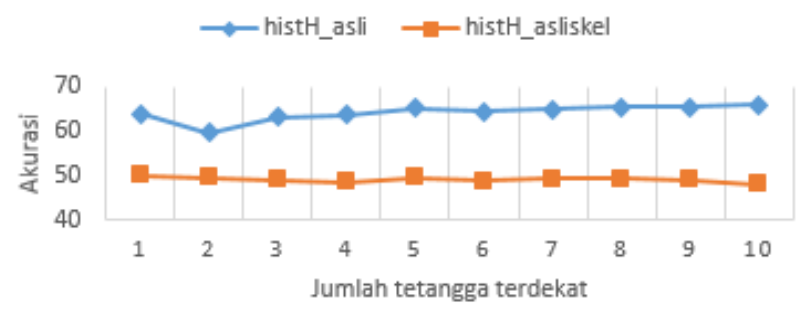

Gbr. 7 Akurasi perbandingan fitur profil proyeksi horisontal pada citra asli dan citra skeleton.

\section{PROFIL PROYEKSI VERTIKAL DAN HORISONTAL}

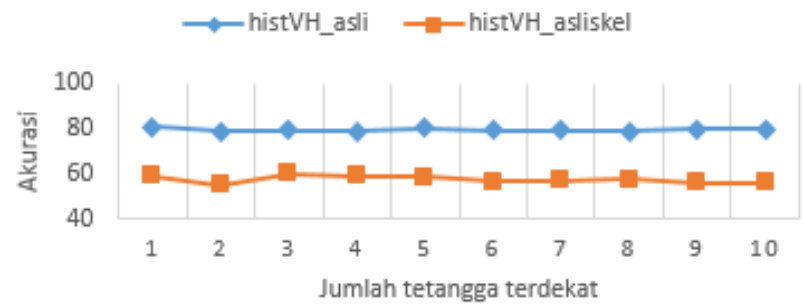

Gbr. 8 Akurasi perbandingan fitur profil proyeksi gabungan (vertikal dan horisontal) pada citra asli dan citra skeleton.

\section{PROFIL PROYEKSI CITRA ASLI}

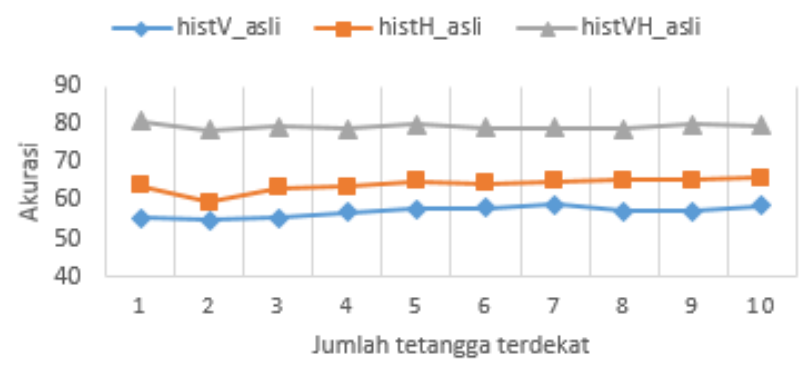

Gbr. 9 Akurasi perbandingan fitur 3 jenis profil proyeksi pada citra asli.

\section{PROFIL PROYEKSI CITRA SKELETON}

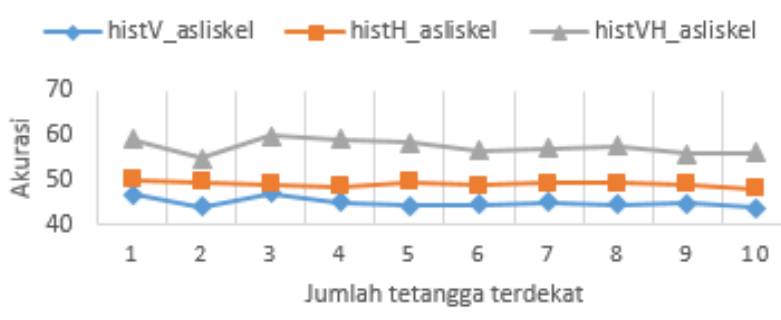

Gbr. 10 Akurasi perbandingan fitur 3 jenis profil proyeksi pada citra skeleton.

Dari semua ujicoba, performa terbaik diperoleh pada parameter $\mathrm{k}-\mathrm{NN} \mathrm{k}=1$, menggunakan fitur profil proyeksi gabungan horisontal dan vertikal, menggunakan citra asli tanpa tahapan skeletoning.

Tabel III menampilkan perbandingan performa metode yang diusulkan dengan penelitian sebelumnya. Meskipun performa metode yang diusulkan belum dapat melampaui penelitin terakhir sebelumnya, tapi sudah lebih baik dari beberapa metode yang dilakukan oleh Purbasari, yaitu penggunaan metode Naïve Bayes dengan/tanpa Adaboost [8]. Tetapi dalam hal waktu uji, metode yang diusulkan melampaui performa hamper semua penelitian sebelumnya.

TABEL III

DISTRIBUSI SAMPEL DATA TIAP KELAS

\begin{tabular}{|l|l|l|}
\hline Metode yang digunakan & $\begin{array}{l}\text { Akurasi } \\
(\%)\end{array}$ & $\begin{array}{l}\text { Waktu } \\
\text { uji (s) }\end{array}$ \\
\hline Original image + ID3 [8] & 100 & 74.16 \\
\hline Original image + Naïve Bayes [8] & 69.37 & 0.67 \\
\hline $\begin{array}{l}\text { Original image + Neural Network } \\
\text { (NN) [8] }\end{array}$ & 84.48 & 1410.79 \\
\hline Original image + ID3 AdaBoost [8] & 100 & 509.71 \\
\hline Original image + NB AdaBoost [8] & 69.96 & 810.29 \\
\hline Original image + NN AdaBoost [8] & 84.48 & 2721.62 \\
\hline Original + 3x3 LBP grid + kNN [9] & 91.33 & 22.3853 \\
\hline $\begin{array}{l}\text { Metode yang diusulkan (profil } \\
\text { proyeksi VH + k-NN) }\end{array}$ & 80.95 & 0.66 \\
\hline
\end{tabular}

IV. KESIMPULAN 
Kesimpulan yang dapat diambil berdasarkan ujicoba yang telah dilakukan meliputi dampak skeletoning dan jenis fitur profil proyeksi. Ekstraksi skeletoning dalam tahapan preprocessing tidak memberikan dampak yang bagus pada performa sistem, dikarenakan menghilangkan banyak data yang bermanfaat untuk pembentukan fitur profil proyeksi. Sedangkan terkait jenis profil proyeksi yang bagus adalah ketika dilakukan penggabungan antara profil proyeksi horisontal dan vertikal.

Untuk penelitian berikutnya akan dikembangkan jenis proyeksi lain dan juga tahapan preprocessing yang mendukung pembentukan profil proyeksi lebih baik.

\section{REFERENSI}

[1] U. Pal and B. B. Chaudhuri, "Indian script charac-ter recognition: A survey," Pattern Recognit. 2004, 37(9), pp.1887-1899.

[2] N.R. Soora, and P.S. Deshpande, "Review of feature extraction techniques for character recognition," IETE Journal of Research, 2018, 64(2), pp.280-295.

[3] M. Javed, P. Nagabhushan, dan B.B. Chaudhuri, "Extraction of projection profile, run-histogram and entropy features straight from run- length compressed text-documents," arXiv preprint arXiv:1404.0627, 2014 .

[4] K.C. Santosh, dan L. Wendling, "Character recognition based on nonlinear multi-projection profiles measure," Frontiers of Computer Science, 2015, 9(5), pp.678-690

[5] G. Vamvakas, B. Gatos, I. Pratikakis, N. Stamatopoulos, A. Roniotis, dan S.J. Perantonis, "Hybrid off-line OCR for isolated handwritten Greek characters," The Fourth IASTED International Conference on Signal Processing, Pattern Recognition, and Applications (SPPRA 2007), pp. 197-202.

[6] M.A. Naser, N.I. Hamid, dan M.A. Hoque, "Projection based feature extraction process for Bangla script: A modified approach," Software Technology And Engineering, 2009, pp. 210-214.

[7] M.K Mahto, K. Bhatia, dan R.K Sharma, "Combined horizontal and vertical projection feature extraction technique for Gurmukhi handwritten character recognition," 2015 International Conference on Advances in Computer Engineering and Applications (pp. 59-65). IEEE.

[8] F. T. Anggraeny, M. S. Munir, dan I. Y. Purbasari, "Handwritten Alphabets Recognition Using Graylevel And Local Binary Patterns (LBP) Feature," in International Joint Conference on Science and Technology (IJCST), 2017, p. E2.4-1-E2..4-5.

[9] I. Y. Purbasari and F. T. Anggraeny, "Perbandingan Algoritma Klasifikasi Untuk Huruf," SCAN J. Teknol. Inf. dan Komun., vol. X, no. 2, pp. 55-62, 2015. 